\title{
Diagnostic strategies in nasal congestion
}

This article was published in the following Dove Press journal:

International Journal of General Medicine

15 February 2010

Number of times this article has been viewed

\section{John Krouse' \\ Valerie Lund ${ }^{2}$ \\ Wytske Fokkens ${ }^{3}$ \\ Eli O Meltzer ${ }^{4}$}

'Temple University School of Medicine, Philadelphia, PA, USA; ${ }^{2}$ Ear Institute, University College London, UK; ${ }^{3}$ Department of Otorhinolaryngology, Amsterdam Medical Centre, Netherlands; ${ }^{4}$ Allergy and Asthma Medical Group and Research Center, San Diego, CA and Department of Pediatrics, University of California, San Diego, USA
Correspondence: John H Krouse Temple University School of Medicine, Kresge West Building, SW Corner Broad and Tioga Streets, Philadelphia, PA, $19 \mid 40$, USA

$\mathrm{Tel}+\mid$ 2|5-707-758 |

Fax + I 2I5-707-7523

Email jkrouse@temple.edu
Abstract: Nasal congestion is a major symptom of upper respiratory tract disorders, and its characterization an important part of the diagnosis of these illnesses. Patient history and assessment of nasal symptoms are essential components of diagnosis, providing an initial evaluation that may be adequate to rule out serious conditions. However, current congestion medications are not always fully effective. Thus, if symptoms do not respond adequately to therapy, or symptoms suggestive of more serious conditions are present, specialized assessments may be needed. Various techniques are available for diagnosing patients, including those used chiefly by primary care clinicians and those requiring the expertise of otolaryngologists, allergists, and other specialists. Endoscopy remains a mainstay for evaluating nasal blockage and its causes, while modalities such as peak nasal inspiratory flow and acoustic rhinometry are evolving to provide easy-to-use, noninvasive procedures that are sensitive enough to measure small but clinically important abnormalities and therapeutic changes. Several imaging modalities are available to the specialist for severe or unusual cases, as are specialized diagnostic procedures that measure adjunctive features of congestion, such as impaired mucociliary function.

Keywords: allergic rhinitis, congestion, diagnosis, obstruction, rhinosinusitis

\section{Introduction}

Nasal congestion is a common symptom of upper respiratory tract disorders and is associated with a range of etiologies. ${ }^{1}$ The task of discerning the severity of the condition and first-line intervention typically falls to primary care clinicians. ${ }^{2}$ Consultation with a specialist may be required for patients with persistent symptoms that do not respond to initial therapies. Specialized diagnostics are needed to rule out nasal polyps, anatomical variation, and nasal manifestations of systemic disease, eg, granulomas. In addition, specialists often find allergy testing to be valuable if allergic rhinitis is suspected.

The challenges facing the clinician treating nasal congestion range from evaluating poorly differentiated early symptoms of complex conditions to sorting out confounding issues in patients who have already been treated for chronic nasal congestion. ${ }^{2}$ Initial evaluation relies heavily on subjective assessment of nasal symptoms by both the doctor and patient. Thus, a detailed patient history plus a limited physical examination provide the foundation for diagnosing congestion. Many additional objective diagnostic techniques, such as endoscopy and allergy testing, are beyond the purview of primary care practice, necessitating referral to specialists, such as otolaryngologists and allergists. For each patient, these physicians must weigh the benefits of using an array of diagnostic interventions against the cost and potential risks. 
This review provides an overview of diagnostic procedures for nasal congestion. In addition, the clinical application of various standard and experimental methods will be discussed.

\section{Differential diagnosis of nasal congestion}

Congestion must be evaluated in the context of related nasal symptoms that often are present, such as discharge, anterior or postnasal drip, facial pain or pressure, and reduction or loss of olfaction., ${ }^{3,4}$

Complicating nasal congestion diagnosis is the fact that it can be a symptom of various disorders, although rhinitis and rhinosinusitis are the most commonly associated conditions (Table 1). ${ }^{1,3}$ Rhinitis may be classified as infectious, allergic, occupational, drug induced, hormonal, or idiopathic (also known as vasomotor). Allergic rhinitis can be further subclassified as either intermittent, if symptoms are present for less than 4 days a week or less than 4 weeks, or persistent, when symptoms are present for more than 4 days a week and for more than 4 weeks. ${ }^{1}$ Additionally, both intermittent and persistent allergic rhinitis can be categorized as mild or moderate-to-severe, depending on the severity of symptoms and quality-of-life (QOL) outcomes. ${ }^{1}$

Rhinosinusitis can be categorized as acute or chronic, based on the duration of symptoms. ${ }^{3}$ Further classification includes acute viral, acute nonviral, or chronic (which can be either with or without nasal polyps). Nasal symptoms due to viral infections are generally acute in nature. Acute viral rhinosinusitis, also known as the common cold, is defined as having symptoms that resolve in $\leq 10$ days. ${ }^{3}$ By definition, symptoms of acute nonviral rhinosinusitis increase after 5 days or persist for more than 10 days. ${ }^{3}$ Despite their relatively short duration, acute nasal symptoms may be more severe than those due to other etiologies. ${ }^{3}$ Although symptoms of acute and chronic rhinosinusitis, including nasal polyposis, may be similar, the pattern of occurrence and their intensity may be distinguishing features. ${ }^{3}$ For example, nasal polyposis is a chronic condition that may be accompanied by congestion and, typically, diminished capacity to smell.

Congestion can also be due to mechanical factors or other less common but serious causes, such as tumors or granulomas.

\section{Initial evaluation of nasal congestion}

Nasal congestion is often the result of a combination of hemodynamic and inflammatory processes that can cause severe obstruction. Nasal epithelia are highly vascularized, and blood volume can expand or contract rapidly in response to thermal, chemical, mechanical, or neurological signals. ${ }^{1}$ Expanded blood volume is a normal part of the rhythmic alternating of congestion and decongestion known as nasal cycling. ${ }^{5}$ However, the increased tissue cellularity and plasma exudation that occur during inflammation may exacerbate obstruction due to vasodilatation. ${ }^{1}$

\section{Patient history and evaluation of symptoms}

Detailed patient history with physical examination is the foundation of nasal congestion diagnosis (Table 1 and Figure 1). This history should include characterization of nasal blockage/congestion; presence of other rhinosinusitis symptoms, such as postnasal discharge, itchy nose, sneezing and eye symptoms; related signs, such as facial pain, headache, and inability to smell; and relevant data (duration of the symptoms, pattern in time, and trigger factors).

A well-established approach to understanding symptom severity from the patient's perspective is to use a visual analog scale (VAS). The VAS allows patients to rate their symptoms on a $10-\mathrm{cm}$ linear scale, where 0 corresponds to symptoms that are not troublesome at all and 10 is the most troublesome imaginable (Figure 2). ${ }^{3}$ The VAS is particularly useful in evaluating nasal blockage and discharge, facial pain or pressure, headache, olfactory disturbance, and overall symptoms.

The International Primary Care Respiratory Group (IPCRG) Guidelines Allergic Rhinitis Questionnaire (Table 2) ${ }^{2}$ is a simple, useful tool for initial characterization of nasal symptoms. It employs two question sets to distinguish patients who probably do not have allergic rhinitis from those who do. ${ }^{2}$ This tool, combined with physical examination, provides a means for identifying symptoms that suggest serious problems warranting immediate referral. Symptoms requiring immediate attention are swollen or red eyelids, displaced globe, double vision, ophthalmoplegia, reduced visual acuity, severe unilateral or bilateral frontal headache, frontal swelling, and signs of meningitis or focal neurological signs. ${ }^{3}$

In another method of assessment, patients self-rate nasal congestion symptoms using a scale of 0 to 3 , where 0 is no awareness of blockage to air flow and 3 is almost complete or complete blockage of air flow through both nostrils that is very annoying and requires mouth breathing almost all or all of the time. This approach has been used in clinical trials to determine concordance between patient and physician perceptions of symptoms. 
Table I Differential diagnosis of nasal congestion

\begin{tabular}{|c|c|c|}
\hline Rhinitis & Duration & Typical other symptoms \\
\hline \multicolumn{3}{|l|}{ Infectious rhinitis } \\
\hline \multirow[t]{2}{*}{ Viral } & $<10$ days & Sneezing, watery rhinorrhea, sore throat \\
\hline & & Purulent discharge, facial pain \\
\hline Bacterial & $>10$ days & \\
\hline Other infectious agents & $>10$ days & \\
\hline \multicolumn{3}{|l|}{ Allergic rhinitis } \\
\hline \multirow[t]{2}{*}{ Intermittent } & $<4$ days/week & $\begin{array}{l}\text { For all allergic rhinitis: Sneezing, watery rhinorrhea, } \\
\text { itch, eye symptoms, lower airway symptoms }\end{array}$ \\
\hline & $<4$ weeks/year & \\
\hline \multirow[t]{2}{*}{ Persistent } & $>4$ days/week & \\
\hline & $>4$ weeks/year & \\
\hline \multicolumn{3}{|l|}{ Occupational rhinitis } \\
\hline Allergic & Usually less when away from workplace & As allergic rhinitis \\
\hline Nonallergic & & Usually mainly nasal blockage, rhinorrhea \\
\hline Drug induced & $\begin{array}{l}\text { Sometimes difficult to make relation, } \\
\text { can be chronic. History! }\end{array}$ & Often rhinosinusitis symptoms \\
\hline Hormonal & $\begin{array}{l}\text { Sometimes difficult to make relation, } \\
\text { can be chronic. History! }\end{array}$ & Other rhinitis symptoms \\
\hline Other causes of rhinitis & $\begin{array}{l}\text { Sometimes difficult to make relation, } \\
\text { can be chronic. History! }\end{array}$ & $\begin{array}{l}\text { Other rhinitis symptoms } \\
\text { Often significant hyperreactivity }\end{array}$ \\
\hline \multicolumn{3}{|l|}{ NARES } \\
\hline \multicolumn{3}{|l|}{ Irritants } \\
\hline \multicolumn{3}{|l|}{ Food } \\
\hline \multicolumn{3}{|l|}{ Emotions } \\
\hline Idiopathic (also called vasomotor) & Chronic, no cause found & $\begin{array}{l}\text { Mainly nasal blockage, sometimes clear history } \\
\text { of hyperreactivity }\end{array}$ \\
\hline \multicolumn{3}{|l|}{ Rhinosinusitis } \\
\hline Acute viral & $<10$ days & Sneezing, watery rhinorrhea, sore throat, facial pain \\
\hline Acute nonviral rhinosinusitis & $\begin{array}{l}>10 \text { days or acute onset and increased } \\
\text { symptoms after } 5 \text { days }<12 \text { weeks }\end{array}$ & Purulent discharge/postnasal drip, facial pain, fever \\
\hline Chronic rhinosinusitis & $>12$ weeks & \\
\hline Without nasal polyps & & Purulent discharge/postnasal drip, facial pain \\
\hline With nasal polyps & & Purulent discharge/postnasal drip, loss of smell \\
\hline \multicolumn{3}{|l|}{ Mechanical factors } \\
\hline Deviated septum & Chronic & Often one side more \\
\hline Adenoidal hypertrophy & Chronic in children & Rhinorrhea, snoring, open-mouth breathing \\
\hline Foreign bodies & (Sub)acute usually children & Purely one side, history!, endoscopy necessary \\
\hline Choanal atresia & One side can stay unnoticed & Also chronic rhinorrhea on one side \\
\hline \multicolumn{3}{|l|}{ Other rarer causes } \\
\hline \multicolumn{3}{|l|}{ Tumors } \\
\hline \multicolumn{3}{|l|}{ Benign } \\
\hline Malignant & Usually longer history but not always & $\begin{array}{l}\text { Mostly unilateral, bleeding; if suspected, ENT } \\
\text { referral }\end{array}$ \\
\hline \multicolumn{3}{|l|}{ Granulomas } \\
\hline Wegener's granulomatosis & Usually longer history but not always & Systemic signs of disease \\
\hline Sarcoid & & \\
\hline
\end{tabular}




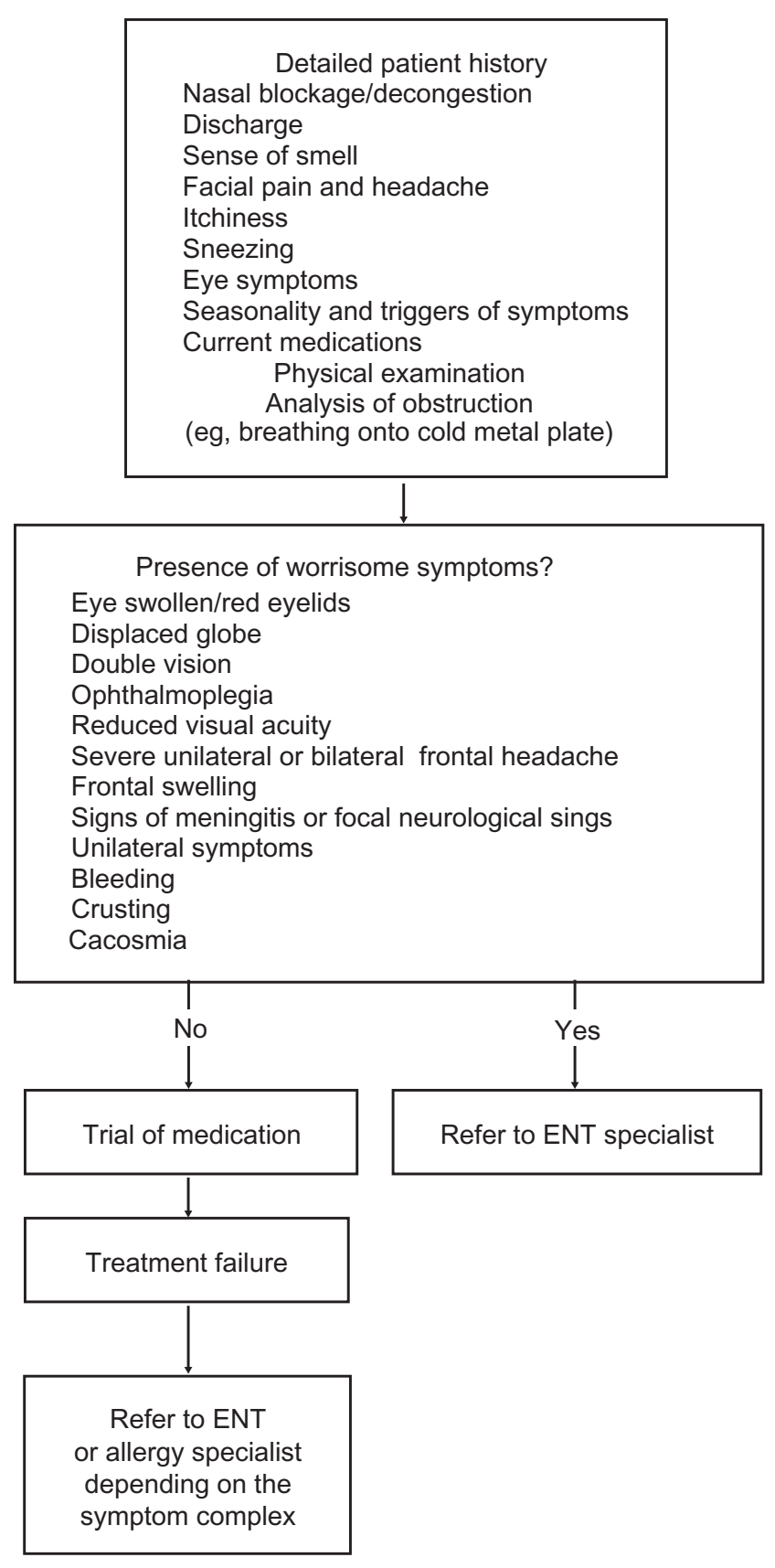

Figure I Diagnostic algorithm for nasal congestion.

The severity of symptoms does not always correlate with the impact of nasal symptoms on an individual's QOL. ${ }^{6} \mathrm{QOL}$ measures that have been used in nasal and sinonasal research include the validated Medical Outcomes Short Form (SF)-36, the most widely used general health status questionnaire; the Rhinoconjunctivitis Quality of Life Questionnaire (RQLQ), an allergic rhinitis disease-specific tool; ${ }^{7}$ and the Sinonasal Outcomes Test (SNOT)-22, a validated health status questionnaire specific for sinonasal disease which was derived from the SNOT-20. ${ }^{8}$ The SNOT-22 is sensitive to clinically meaningful change and has proven useful in monitoring response to treatment in patients with chronic rhinosinusitis and following septal surgery. ${ }^{8,9}$

Recently, a simple, patient-completed instrument was developed and validated to specifically identify patients with congestion. This screening tool, the Congestion Quantifier seven-item test (CQ7), has been demonstrated in a large clinical study to be reliable, valid, and responsive to changes in severity of nasal congestion. ${ }^{10}$ The CQ7 is designed to identify congestion warranting clinical evaluation and help patients make decisions about seeking treatment. ${ }^{10}$ In addition, this questionnaire and the CQ5 can be used to document whether a meaningful change has occurred following an intervention. ${ }^{11}$

Overall, patient history provides the best knowledge of the subjective patient perception of disease severity but does not provide objective data on disease etiology. The latter may require evaluation by a specialist. If there are no worrisome symptoms present and medical treatment for bacterial infection has been ruled out, analgesics and/or antihistamines or topical steroids may be initiated. Evaluation time depends on the severity and acuteness of the symptoms. If no improvement has occurred in a reasonable time (such as 2 to 4 weeks), a more extensive work-up may be needed, and the patient should be referred to the appropriate specialist.

\section{Diagnostic tools that can be utilized in primary care Rhinoscopy}

Anterior rhinoscopy, conveniently performed with an otoscope or with a nasal speculum and headlight, provides limited information, although it may be appropriate in severe cases or if there are major changes in a patient's condition. However, it is not adequate for diagnosis. ${ }^{12,13}$ A straightforward evaluation of the extent of nasal blockage may be performed by having the patient breathe out with mouth closed onto a cold metal surface. Definitive diagnosis, however, requires endoscopic evaluation by a specialist. ${ }^{3}$ For individuals who are diagnosed with chronic or persistent rhinosinusitis or nasal polyposis, response to treatment should be evaluated after 4 weeks.

\section{Allergy testing}

Diagnosis of allergic rhinitis is based on the combination of a typical history of allergic symptoms and relevant diagnostic tests. ${ }^{13}$ In vivo and in vitro tests for diagnosis of allergic diseases are skin prick testing or measurement of serum-specific immunoglobulin (Ig)E to aeroallergens. Allergy diagnosis has been 


\section{Please mark the line to indicate how troublesome you find your nasal symptoms to be.}

\section{Not troublesome $\longmapsto \begin{gathered}10 \mathrm{~cm} \\ \begin{array}{c}\text { Most troublesome } \\ \text { imaginable }\end{array}\end{gathered}$}

Figure 2 Visual analog scale for assessment of symptom severity. Adapted with permission from Fokkens W, Lund V, Mullol J. European position paper on rhinosinusitis and nasal polyps 2007. Rhinol Suppl. 2007;(Suppl 20):I-136. ${ }^{3}$ Copyright @) 2007 International Rhinologic Society.

improved by allergen standardization, providing satisfactory extracts for both in vivo and in vitro tests for most inhalant allergens. Pharmaceutical agents affect skin tests, especially antihistamines, and it is always necessary to ask patients about the medications they have taken. It may not be possible to test patients with dermographism (urticaria) or widespread skin lesions. ${ }^{13}$ Although skin testing is generally safe and well tolerated among adults, adolescents, and children, care should be taken in diagnosing allergies in young children.

\section{Medication trial as diagnostic}

For many patients, including those who are referred for allergy testing, a trial of medication can be initiated, and the intensity of treatment may be driven by the impact of symptoms on patient function. Although subjective analyses of symptoms by patients or physicians may not provide a definitive diagnosis, they may guide initial treatment and provide insight into therapeutic response. Importantly, in many patients, congestion cannot be completely relieved with any currently available medication. ${ }^{12}$

\section{Comprehensive diagnostic tools for specialists and clinical researchers Allergy}

Allergy skin testing is the primary modality used in the diagnosis of allergic diseases; analysis of skin prick tests from more than 11,000 European patients showed specificity exceeding 93\% and sensitivity over $63.4 \% .{ }^{14}$ Skin testing results guide development of treatment and avoidance strategies. ${ }^{15}$ Various skin testing devices have been developed in an effort to improve test standardization and to decrease discomfort for the patient.

\section{Endoscopy}

Endoscopy provides intense illumination and magnification of the nasal passages and is indicated for patients who experience chronic or recurrent acute rhinosinusitis symptoms, or those with suspected sinonasal polyposis. ${ }^{16}$ This technique can be used more effectively than simple anterior rhinoscopic examination to diagnose anatomical variations that may cause nasal congestion, as well as to observe signs

Table 2 Allergic rhinitis questionnaire

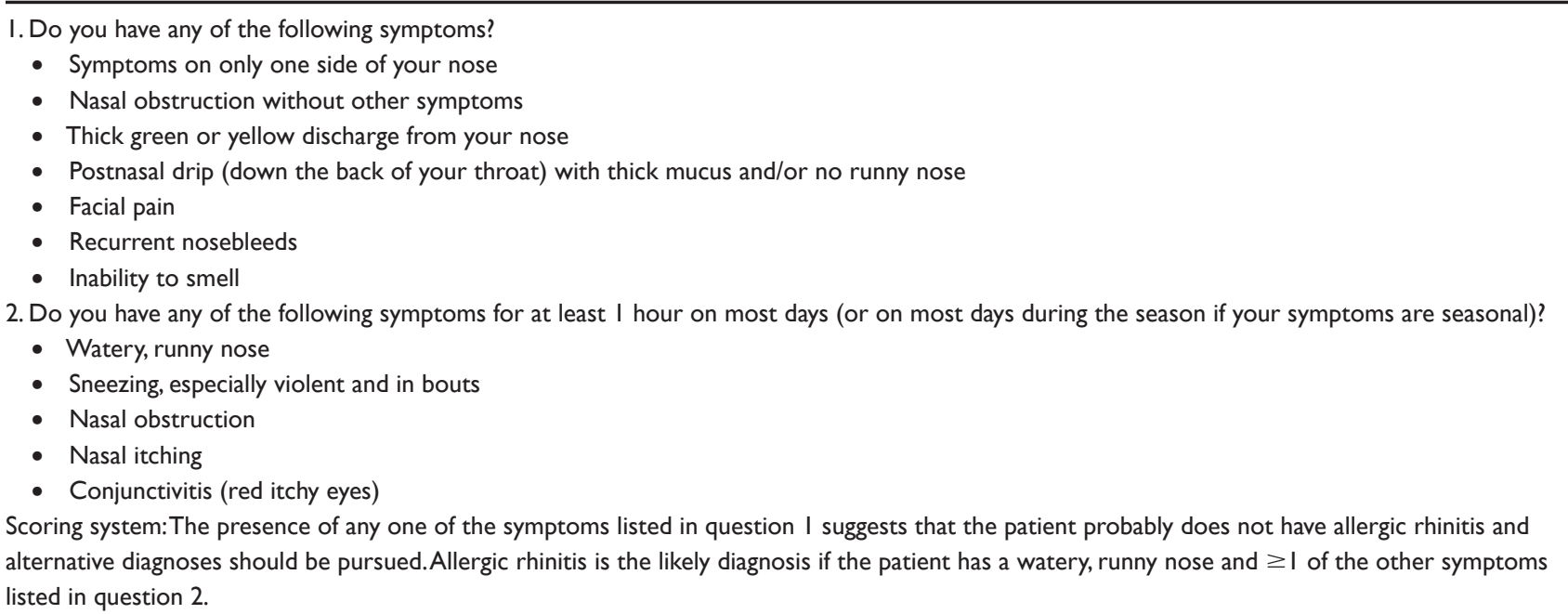

Reprinted with permission from Primary Care Respiratory Journal - [DOI: http://dx.doi.org//0.1016/j.pcrj.2005.10.004] Reference: - Mark L Levy, Monica Fletcher, David B Price, Thomas Hausen, Ron J Halbert, Barbara PYawn. International Primary Care Respiratory Group (IPCRG) Guidelines: Diagnosis of respiratory diseases in primary care. PCRJ. 2006; I5(I): 20-34. Full text of this article is available online at [DOI: http://dx.doi.org//0.1016/j.pcri.2005.10.004] 
of crusting and pus indicative of ongoing infection. ${ }^{16}$ In one comparative study, endoscopy detected nasal pathology in $38.7 \%$ more patients than anterior and posterior rhinoscopic examination. ${ }^{16,17}$ In clinical practice, nasal endoscopy also can be used by allergists and ENT specialists to assess response to medical and surgical therapy. In addition, videoenhanced endoscopy can be a useful teaching tool to help patients better understand their condition and the rationale for treatment. ${ }^{16}$

Results of endoscopic examinations can be quantified using various rating scales that include numeric ratings of polyps, discharge/rhinorrhea, edema, scars, or adhesions and crusting. ${ }^{18}$ For example, a staging scale for nasal polyps could use: $0=$ none; 1 = within middle meatus; $2=$ outside middle meatus but not completely obstructing the nose; $3=$ complete obstruction. Many permutations of this scoring system exist. ${ }^{18,19}$ Although rating scales are useful for clinical studies, they are of limited use in everyday evaluation. Other endoscopic evaluations could include the size of the turbinates and examination of sinus ostia. The benefits of endoscopy are many, and the procedure is well tolerated by most patients. However, this procedure can result in minor pain or discomfort and occasional bleeding.

\section{Imaging}

Routine ordering of computed tomography (CT) scans and magnetic resonance imaging (MRI) to evaluate nasal congestion is not justified, although these modalities may be indicated rarely for difficult cases such as suspected neoplasia. $^{3}$

CT scan-dependent staging does not correlate well with disease symptoms. ${ }^{20}$ MRI can be overly sensitive when used to assess sinus mucosal disease. Incidental findings of abnormal mucosal changes in patients undergoing MRI for nonrhinologic disease have been reported in $31.7 \%$ to $55 \%$ of cases. ${ }^{21} \mathrm{~A}$ recent study showed no significant correlation between rhinologic symptoms and radiologic features suggestive of rhinosinusitis in patients undergoing MRI for unrelated disease. The authors conclude that treatment of rhinosinusitis should be guided by nasal history and endoscopy rather than radiologic findings. ${ }^{21}$

\section{Nasal smears, swabs, and biopsy}

Nasal smears and swabs may assist in the identification of etiologic agents in infectious bacterial rhinosinusitis. A meta-analysis of studies conducted between 1966 and 2003 found that middle meatal cultures procured using noninvasive endoscopic techniques have a high concordance with maxillary sinus aspirates. ${ }^{22}$ Therefore, middle meatus cultures can substitute for sinus aspirates in most situations but biopsy and nasal cytology are less readily available for routine clinical care. Nasal cytology may help differentiate between various inflammatory and noninflammatory nasal diseases and document a response to therapy. However, results depend on the quality of the specimen and evaluator. $^{23,24}$

A comparison of CT scans, endoscopy scores, and SNOT-20 scores with molecular, cellular, and histologic markers in patients with chronic rhinosinusitis found that eosinophilia correlated with higher CT and endoscopy scores. However, symptom scores did not correlate with any of the studied markers. Thus, the clinical application of this approach is not established..$^{25}$

\section{Mucociliary function}

Mucociliary clearance is affected by the consistency of mucus coating the nasal epithelium, which can influence the sensation of congestion. In the presence of normal mucociliary function, a small amount of placed saccharin placed just behind the anterior end of the inferior turbinate will be carried backwards to the nasopharynx and a sweet taste detected. In a recent study, clearance time as measured by the saccharin test did not appear to correlate with SNOT-20 scores of symptom severity. ${ }^{26}$ Ciliary function measurements using brushings, electron microscopy, and epithelial cell cultures may also be useful in confirming inherited problems such as primary ciliary dyskinesia.

\section{Nitric oxide expiration}

Nitric oxide (NO) is released in large quantities by the tissues of the paranasal sinuses in healthy individuals; NO release is altered in a number of respiratory disorders, such as allergic rhinitis and rhinosinusitis. ${ }^{27}$ Interest has developed in the diagnostic application of measuring changes in expired NO in the setting of rhinosinusitis, because this completely noninvasive procedure is easy to perform. For most applications, NO measurement is still considered experimental but holds promise for future clinical applications. ${ }^{27}$

\section{Olfaction testing and systemic testing}

Although olfaction is affected by congestion in many patients, testing is of limited diagnostic benefit. A variety of olfactory tests are available, which are primarily of benefit in clinical research settings or specialty clinics.

Laboratory blood tests may provide information on broader infection or other pathology in difficult or unusual 
cases (eg, Wegener's granulomatosis, sarcoidosis). Laboratory work-up should include a complete and differential blood count. Erythrocyte sedimentation rate and C-reactive protein levels can indicate the extent of systemic inflammation, and cytoplasmic-staining antineutrophil cytoplasmic antibodies (such as to proteinase 3 ) are useful markers for vasculitides such as Wegener's granulomatosis. ${ }^{28}$

Sarcoidosis screening may involve interpretation of serum angiotensin-converting enzyme (SACE) levels. These interpretations should be made in the context of the patient's specific genotype. Although SACE testing is done routinely in many clinical laboratories, the validity of the results is questionable unless the test has been performed in a specialized setting. ${ }^{29}$

\section{Nasal airway patency assessment}

In clinical practice, assessing nasal patency in congestion is warranted only if surgery is considered or moderate-to-severe obstruction is the patient's chief complaint. ${ }^{30}$

The "ideal" test of nasal patency is simple, easy to interpret, durable, and cost-effective. It should be a standardized, noninvasive, rapid, and reproducible technique with high resolution and universal application. Currently available objective diagnostic tests are rhinomanometry, peak nasal inspiratory flow (PNIF), and acoustic rhinometry (Table 3).

In the United States, unlike Europe, rhinometry and rhinomanometry are infrequently used by allergists or ENT specialists and employed mostly for research trials. Because it functionally tests nasal aerodynamics, rhinomanometry may be preferable for evaluating nasal stuffiness, while rhinometry is more helpful in locating the position of nasal obstruction (Figure 3). ${ }^{30}$

\section{Summary}

Diagnostic strategies for nasal congestion rely on patient history and symptom evaluation as the foundation for making treatment decisions. Allergy testing and endoscopy are widely used for this patient population. However, despite the development of numerous objective measures of disease severity, most fail to accurately reflect the severity of the symptoms and their impact on QOL as perceived by the patient. Because the intensity of treatment is dictated primarily by patient perceptions of symptoms, the use of more sophisticated

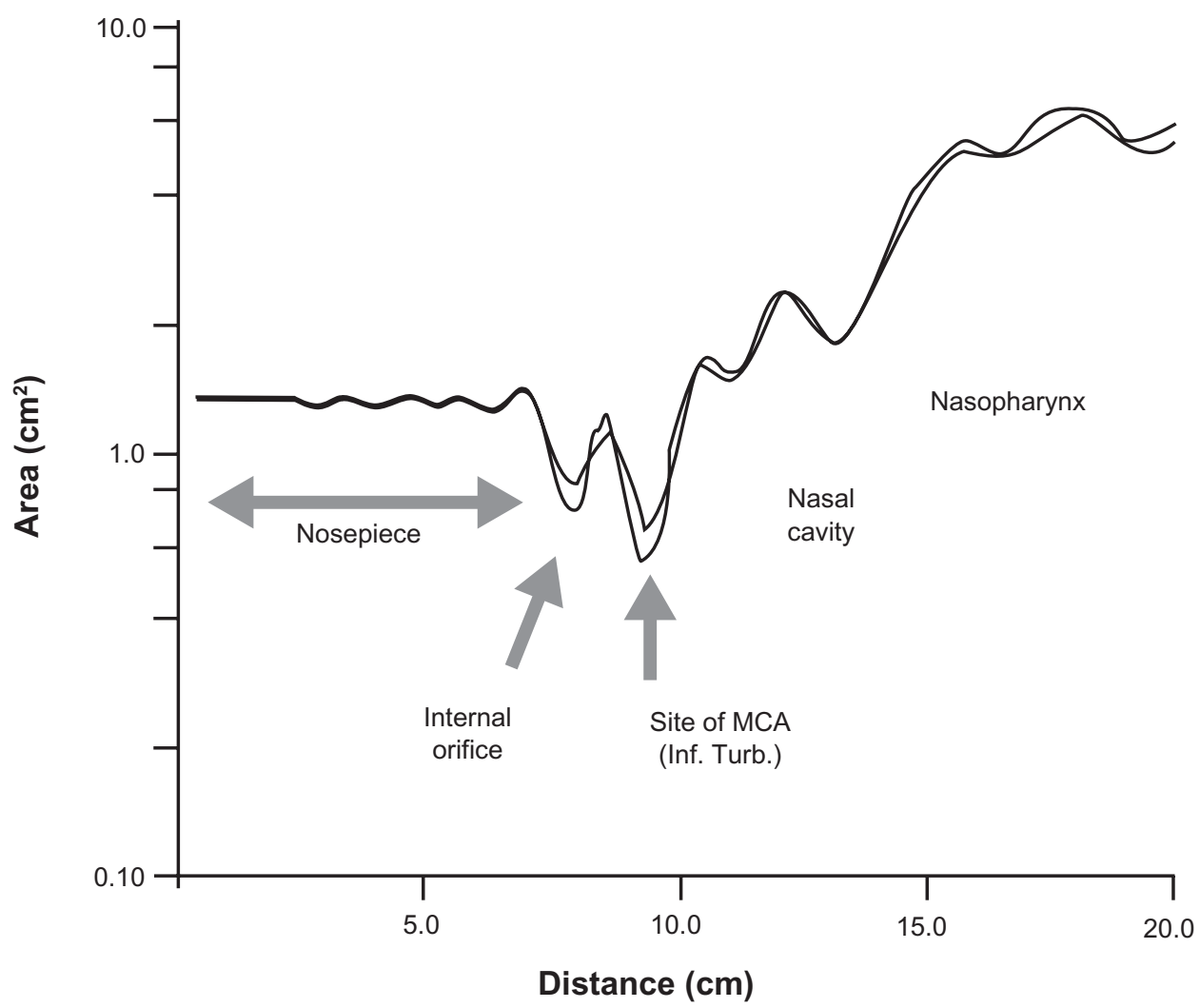

Figure 3 Acoustic rhinometry trace. Results of three superimposed rhinometry traces of the left nostril demonstrate the high reproducibility of this technique. Abbreviations: MCA, minimal cross-sectional area; Inf. turb., inferior turbinate. 
Table 3 Assessment tools for nasal congestion

\begin{tabular}{ll}
\hline Subjective measures & Objective measures \\
\hline Visual analog scale (VAS) & Nasal endoscopy \\
Congestion Quantifier seven-item test (CQ7) & Nasal peak flow (inspiratory and expiratory) \\
Congestion Quantifier five-item test (CQ5) & Rhinoscopy \\
Sinonasal Outcomes Test (SNOT)-22 & Rhinomanometry \\
Congestion symptom score (CSS) of total nasal symptom score (TNSS) & Acoustic rhinometry \\
International Primary Care Respiratory Group Guidelines Allergic Rhinitis Questionnaire & Computerized tomography (CT scan) \\
Rhinoconjunctivitis Quality of Life Questionnaire (RQLQ) & Magnetic resonance imaging (MRI) \\
Medical Outcomes Short Form-36 & Rhinostereometry \\
& Nasal spirometer \\
\hline
\end{tabular}

diagnostic interventions may be reserved for unusual or difficult-to-diagnose cases.

\section{Acknowledgments}

Editorial assistance was provided by Henry Hamilton, $\mathrm{PhD}$, former employee of Health Science Communications, Inc., and Joyce O'Connor, MS of Health Science Communications, Inc. This assistance was funded by Schering-Plough Corporation, now Merck \& Co., Whitehouse Station, NJ, USA.

\section{Disclosures}

Dr Krouse: consultant to Schering-Plough Corporation, now Merck \& Co., Whitehouse Station, NJ, USA and Alcon Labs.

Dr Fokkens: none.

Dr Lund: Consultancy work/advisory panel member for Schering-Plough Corporation, now Merck \& Co., Whitehouse Station, NJ, USA, Medtronic; investigator for GlaxoSmithKline.

Dr Meltzer: grant/research support from the following: Alcon, Amgen, Apotex, AstraZeneca, Boehringer Ingelheim, Capnia, Genentech, GlaxoSmithKline, MAP Pharmaceuticals, Meda, Merck, Novartis, Pharmaxis, Sanofi-aventis, Schering-Plough Corporation, now Merck \& Co., Whitehouse Station, NJ, USA, Sepracor, Skye Pharma, Teva, Vocel, Wyeth. Consultant/speaker for the following: Abbott, Alcon, Amgen, AstraZeneca, Capnia, Dey, Evolutec, Genentech, GlaxoSmithKline, Greer, Inspire, Johnson \& Johnson, MAP Pharmaceuticals, Meda, Merck, Novartis, Pfizer, sanofi-aventis, Schering-Plough Corporation, now Merck \& Co., Whitehouse Station, NJ, USA, Sepracor, Shionogi, VentiRx, Wyeth.

\section{References}

1. Bousquet J, Van Cauwenberge P, Khaltaev N. Allergic rhinitis and its impact on asthma. J Allergy Clin Immunol. 2001;108(5 Suppl): S147-S334.
2. Levy ML, Fletcher M, Price DB, Hausen T, Halbert RJ, Yawn BP. International Primary Care Respiratory Group (IPCRG) guidelines: diagnosis of respiratory diseases in primary care. Prim Care Respir J. 2006;15(1):20-34.

3. Fokkens W, Lund V, Mullol J. European position paper on rhinosinusitis and nasal polyps 2007. Rhinol Suppl. 2007;(Suppl 20):1-136.

4. van Spronsen E, Ingels KJ, Jansen AH, Graamans K, Fokkens WJ. Evidence-based recommendations regarding the differential diagnosis and assessment of nasal congestion: using the new GRADE system. Allergy. 2008;63(7):820-833.

5. Baraniuk JN, Kim D. Nasonal reflexes, the nasal cycle, and sneeze. Curr Allergy Asthma Rep. 2007;7:105-111.

6. Radenne F, Lamblin C, Vandezande LM, et al. Quality of life in nasal polyposis. J Allergy Clin Immunol. 1999;104(1):79-84.

7. Juniper EF, Thompson AK, Ferrie PJ, Roberts JN. Validation of the standardized version of the Rhinoconjunctivitis Quality of Life Questionnaire. J Allergy Clin Immunol. 1999;104(2 Pt 1):364-369.

8. Hopkins C, Gillett S, Slack R, Lund VJ, Browne JP. Psychometric validity of the 22-item Sinonasal Outcome Test. Clin Otolaryngol. 2009;34(5):447-454.

9. Buckland Jr, Thomas S, Harries PG. Can the Sino-nasal Outcome Test (SNOT-22) be used as a reliable outcome measure for successful septal surgery? Clin Otolaryngol Allied Sci. 2003;28(1):43-47.

10. Stull DE, Krouse J, Meltzer EO, et al. Development and validation of the Congestion Quantifier seven-item test (CQ7): a screening tool for nasal congestion. Value Health. 2007;10(6):457-465.

11. Stull DE, Vernon MK, Meltzer EO, Canonica G, Sandor DW, Crespi S. Comparison of Congestion Quantifiers 5 and 7 item scales to monitor nasal congestion [abstract]. J Allergy Clin Immunol. 2008;121(Suppl):S129.

12. Bousquet J, Van Cauwenberge P, Khaltaev N. Allergic rhinitis and its impact on asthma. J Allergy Clin Immunol. 2001;108(Suppl): S147-S334.

13. Bousquet J, Khaltaev N, Cruz AA, et al. Allergic Rhinitis and its Impact on Asthma (ARIA) 2008 updated (in collaboration with the World Health Organization, GA²LEN and AllerGen). Allergy. 2008;63(Suppl 86): $8-160$.

14. Bousquet PJ, Chatzi L, Jarvis D, Burney P. Assessing skin prick tests relieability in ECRHS-1. Allergy. 2008;63:341-346.

15. Carr WW. Improvements in skin-testing technique. Allergy Asthma Proc. 2006;27(2):100-103.

16. Batra PS. The role of endoscopy in the allergist's office. Curr Allergy Asthma Rep. 2006;6(3):228-231.

17. Levine HL. The office diagnosis of nasal and sinus disorders using rigid nasal endoscopy. Otolaryngol Head Neck Surg. 1990; 102(4):370-373.

18. Lund VJ, Mackay IS. Staging in rhinosinusitus. Rhinology. 1993;31(4):183-184.

19. Meltzer EO, Hamilos DL, Hadley JA, et al. Rhinosinusitis: developing guidance for clinical trials. J Allergy Clin Immunol. 2006;118(5 Suppl): S17-S61. 
20. Krouse JH. Computed tomography stage, allergy testing, and quality of life in patients with sinusitis. Otolaryngol Head Neck Surg. 2000;123(4):389-392.

21. McNeill E, O'Hara J, Carrie S. The significance of MRI findings for non-rhinological disease. Clin Otolaryngol. 2006;31(4):292-296.

22. Dubin MG, Ebert CS, Coffey CS, Melroy CT, Sonnenburg RE, Senior BA. Concordance of middle meatal swab and maxillary sinus aspirate in acute and chronic sinusitis: a meta-analysis. Am J Rhinol. 2005;19(5):462-470.

23. Howarth PH, Persson CG, Meltzer EO, Jacobson MR, Durham SR, Silkoff PE. Objective monitoring of nasal airway inflammation in rhinitis. J Allergy Clin Immunol. 2005;115(3 Suppl 1):S414-S441.

24. Meltzer EO, Orgel HA, Jalowayski AA. Nasal cytology. In: Naclerio RM, Durham SR, Mygind N, editors. Rhinitis: mechanisms and management. New York, NY: Informa Healthcare; 1999. p. 175-202.

25. Kountakis SE, Arango P, Bradley D, Wade ZK, Borish L. Molecular and cellular staging for the severity of chronic rhinosinusitis. Laryngoscope. 2004;114(11):1895-1905.
26. Boatsman JE, Calhoun KH, Ryan MW. Relationship between rhinosinusitis symptoms and mucociliary clearance time. Otolaryngol Head Neck Surg. 2006;134(3):491-493.

27. Silkoff PE, Erzurum SC, Lundberg JO, et al. ATS workshop proceedings: exhaled nitric oxide and nitric oxide oxidative metabolism in exhaled breath condensate. Proc Am Thorac Soc. 2006;3(2):131-145.

28. Hagen EC, Daha MR, Hermans J, et al. Diagnostic value of standardized assays for anti-neutrophil cytoplasmic antibodies in idiopathic systemic vasculitis. EC/BCR Project for ANCA Assay Standardization. Kidney Int. 1998;53(3):743-753.

29. Muller BR. Analysis of serum angiotensin-converting enzyme. Ann Clin Biochem. 2002;39(Pt 5):436-443.

30. Schumacher MJ. Nasal congestion and airway obstruction: the validity of available objective and subjective measures. Curr Allergy Asthma Rep. 2002;2:245-251.
International Journal of General Medicine

\section{Publish your work in this journal}

The International Journal of General Medicine is an international peer-reviewed open-access journal that focuses on general and internal medicine, pathogenesis, epidemiology, diagnosis, monitoring and treatment protocols. The journal is characterized by the rapid reporting of reviews, original research and clinical studies across all disease areas.

\section{Dovepress}

A key focus is the elucidation of disease processes and management protocols resulting in improved outcomes for the patient.The manuscript management system is completely online and includes a very quick and fair peer-review system. Visit http://www.dovepress.com/ testimonials.php to read real quotes from published authors.

Submit your manuscript here: http://www.dovepress.com/international-journal-of-general-medicine-journal 